\title{
Phytochemical analysis of Nigerian and Egyptian henna (Lawsonia inermis L.) leaves using TLC, FTIR and GCMS
}

\author{
Nasir Hassan Wagini ${ }^{1, ~ *, ~ A m i r a ~ S h a w k y ~ S o l i m a n ~}{ }^{2}$, Mohamed Said Abbas ${ }^{2}$, Yasser Adel Hanafy ${ }^{3}$, \\ El-Saady Mohamed Badawy ${ }^{4}$
}

\author{
${ }^{1}$ Department of Biology, Faculty of Natural and Applied Sciences, Umaru Musa Yar'adua University, Katsina, Nigeria \\ ${ }^{2}$ Department of Natural Resources, Institute of African Research and Studies, Cairo University, Cairo, Egypt \\ ${ }^{3}$ Medical and Aromatic Plants Unit, Desert Research Center, Cairo, Egypt \\ ${ }^{4}$ Medicinal and Ornamental Plant, Faculty of Agriculture, Cairo University, Cairo, Egypt
}

\section{Email address:}

nhwagini@yahoo.com(N. H. Wagini), sitamira2000@yahoo.com (A. S. Soliman), msaelsarawy@yahoo.com (M. S. Abbas), yasser123oka@yahoo.com (Y. A. Hanafy), saady.badawy@ymail.com(El-Saady M. Badawy)

\section{To cite this article:}

Nasir Hassan Wagini, Amira Shawky Soliman, Mohamed Said Abbas, Yasser Adel Hanafy, El-Saady Mohamed Badawy. Phytochemical Analysis of Nigerian and Egyptian Henna (Lawsonia Inermis L.) Leaves using TLC, FTIR and GCMS. Plant.

Vol. 2, No. 3, 2014, pp. 27-32. doi: 10.11648/j.plant.20140203.11

\begin{abstract}
This study designed to compare phytochemicals for both Nigerian and Egyptian henna using preliminary test for secondary metabolites, thin layer chromatography (TLC), Fourier Transform Infrared spectroscopy (FTIR), and Gas Chromatography Mass spectroscopy (GCMS). Lawsonia inermis L. (Lythraceae) commonly called henna known for its cosmetic properties. The active ingredients in the leaves were extracted and fractionated using chloroform, ether, methanol, and ethyl-acetate. The resultant fractions primarily analyzed for secondary metabolites and secondarily. The phytochemical screening revealed the presence of alkaloids, flavonoids, glycosides, saponins, tannins, quinines, resins and sterols. The presence or absence of all the phytochemicals in these solvents was more or less similar between both samples. TLC profiling shows 9 bands of chemical compounds that are significantly similar in both samples. The FTIR spectrum confirmed the presence of 8 functional in both samples and an additional of aliphaticiodo compound in Egyptian sample. Sixteen and seventeen compounds identified in Nigerian and Egyptian samples respectively by GCMS analysis. Lawsone (2-hydroxy 1, 2-naphtoquinone) is one out of 7 common chemical compounds identified in both samples. The common compound identified by TLC, FTIR, and GCMS were found to be significantly similar in both quantity and quality. Thus, the research confirmed henna to be an important source of phytochemicals of immense pharmaceutical significance.
\end{abstract}

Keywords: Henna, Lawsonia Inermis, Phytochemicals, Nigeria, Egypt

\section{Introduction}

Henna is a perennial shrub native to North Africa, Asia and Australia. It is naturalized and cultivated in the tropics of America, Egypt, India and parts of the Middle East [1]. It is widely distributed across the Northern and Southern parts of Nigeria [2]. Henna is mostly grown in home gardens and commercial production is limited to a few places in India, Pakistan, Iran, Egypt, Libya, Niger, Nigeria and Sudan [3]. Also known as El-Henna, Egyptian priest, and mignonette tree [4]. The scientific name of the henna plant is Lawsonia inermis, belongs to Lythraceae, also known as the loosestrife family and the species is sometimes classified as Lawsonia alba Lam. or Lawsonia ruba $\mathrm{L}$. It is a shrub that grows in North Africa and Middle East [5]. The plant reaches a height of up to 6 meters, and it has a fragrant white or rose-red flower [6]. Although henna is traditionally drawn only on the hands and feet, feel free to create your designs on arms, legs, around the belly button, and even behind the neck [7]. Lawsonia is named after Isaac Lawson, an 18th century Scottish army doctor who was a friend of Linnaeus, and inermis is a Greek word means unarmed without spines [8]. Several researchers have reported the different biological actions of $L$. inermis in various in-vitro and in-vivo test models. Henna leaves, flower, seeds, stem bark and roots have been found to exhibit antioxidant, antidiabetic, hepatoprotective, hypoglycemic, antimicrobial, anticancer and wound healing properties [9]. However, phytochemical screening of henna plant has revealed the presence of numerous chemicals 
including alkaloids, tannins, flavonoids, steroids, glycosides, saponins etc. ([10] and [11]). This study designed to compare the phyto-constituents in Nigerian and Egyptian henna by preliminary test for secondary metabolites, and by techniques of; thin layer chromatography (TLC), Fourier Transform Infrared spectroscopy (FTIR), and Gas Chromatography Mass spectroscopy (GCMS).

\section{Materials and Methods}

\subsection{Collection and Processing of Plant Material}

The Nigerian henna sample collected from Wagini town $60 \mathrm{~km}$ east of Katsina in Batsari Local Government Area of Katsina State and it identified as Lawsonia inermis using available information in the Department of Biology, Umaru Musa Yar'adua University, Nigeria. The Egyptian henna was collected from Central Cairo, Egypt and transported to Desert Research Center Egypt where it was identified as Lawsonia inermis. Both samples were collected in June, 2012. The air dried leaves of the plant from both countries were ground into fine powder using mortar and pestle in the laboratory and stored in air tight polythene bags until use.

\subsection{Extraction of Plant Materials}

The extraction had been carried out according to the method described by Fariba et al., (2010) [12]. The dried extracts kept in a freezer until required for further analysis [13].

\subsubsection{Phytochemical Screening of the Plant Extract}

Phytochemical test was conducted to identify the presence or absence of secondary metabolites namely; alkaloids, flavanoids, glycosides, saponins, tannins, quinines, carbohydrates, resins, sterols and lipid/fat according to the method outlined by [14].

\subsubsection{Thin Layer Chromatography (TLC)}

Extracts of Nigerian and Egyptian henna were spotted in preparative TLC plates coated with silica gel with n-hexane solution and the different spots developed were observed by means of UV light at 1 max $254 \mathrm{~nm}$ and the retention time (Rf) were correspondingly calculated and recorded [15].

\subsubsection{GC-MS Analysis}

GC-MS analysis carried out on a GC Clarus 500 Perkin Elmer system and gas chromatograph interfaced to a mass spectrometer (GC-MS) instrument. The name, molecular weight and structure for the components of the test materials ascertained, compared and recorded [11].

\subsubsection{FTIR Spectroscopic Analysis}

The extracts were examined under FTIR spectrophotometer and they were centrifuged at $3000 \mathrm{rpm}$ for $10 \mathrm{~min}$ and filtered through Whatmann No. 1 filter paper by using high pressure vacuum pump. The peak values of the FTIR were recorded. Each and every analysis was repeated twice for the spectrum confirmation [10].
However, all the data obtained were evaluated using one way analysis of variance.

\section{Result and Discussion}

The preliminary phytochemical qualitative screening of the leaves of $L$. inermis revealed the presence of 10 secondary metabolites namely; alkaloids, flavonoids, glycosides, saponins, tannins, quinines, carbohydrates, resins, sterols and lipid/fat in the fractions of both Nigerian and Egyptian henna, the result is summarized in Table (1). The various phytochemical compounds detected are known to have beneficial importance in industrial and medicinal sciences. There are records that show the benefits of these compounds detected from Lawsonia inermis for example: Saponin is used as a mild detergent and in intracellular histochemistry staining to allow antibody access to intracellular proteins. In medicine, it is used in hyperchloles-trolaemia, hyperglycaemia, antioxidant, anticancer, anti-inflammatory, and weight loss etc. It is also known to have antimicrobial properties [16]. Plant steroids are known to be important for their cardiotonic, insecticidal and anti-microbial properties. They are also used innutrition, herbal medicine, cosmetics and they are routinely used in medicine because of their profound biological activities [17]. Tannin is reported to exhibit antiviral, antibacterial, anti-tumor activities. It was also reported that certain tannin are able to inhibit HIV replication selectivity and is also used as diuretic [18]. Plant tannin has been recognized for their pharmacological properties and is known to make trees and shrubs a difficult meal for many caterpillars [16]. The presence or absence of all the phytochemicals in these four solvents was more or less similar between two different samples. This proved no qualitative different between Nigerian and Egyptian henna base on the present or absent of individual secondary metabolite. 6 phytochemicals (alkaloids, saponins, tannins, carbohydrates, sterols and lipid/fat) were present in all the fractions. Resin was absent only in ether fractions, while flavonoids and glycosides were only present in ether fraction and absent in all the remaining fractions. Kawo and

Table 1. Preliminary screening of secondary metabolites in the fractions of Nigerian ( $N$ ) and Egyptian (E) Lawsonia inermis L. (henna) leaves extract

\begin{tabular}{ccccccccc}
\hline & \multicolumn{3}{c}{ Ether } & \multicolumn{2}{c}{$\begin{array}{c}\text { Methanol } \\
\text { fraction }\end{array}$} & \multicolumn{2}{c}{$\begin{array}{c}\text { Ethyl- } \\
\text { acetate }\end{array}$} & \multicolumn{2}{c}{$\begin{array}{c}\text { Chloroform } \\
\text { Fraction }\end{array}$} \\
& N & E & N & E & N & E & N & E \\
\hline Alkaloids & + & + & + & + & + & + & + & + \\
Flavonoids & + & + & - & - & - & - & - & - \\
Glycosides & + & + & - & - & - & - & - & - \\
Saponins & + & + & + & + & + & + & + & + \\
Tannins & + & + & + & + & + & + & + & + \\
Quinones & + & + & + & + & - & - & + & + \\
Carbohydrates & + & + & + & + & + & + & + & + \\
Resins & - & - & + & + & + & + & + & + \\
Sterols & + & + & + & + & + & + & + & + \\
Lipids/Fat & + & + & + & + & + & + & + & + \\
\hline
\end{tabular}

Key: $+=$ Present $-=$ Absent 
Kwa (2011) [13] reported that the variation in the present or absent of the secondary metabolites in the fractions of plant extracts was due to the differences in the solubility of the metabolites content of the sample in a particular solvent. Phytochemicals; alkaloids, carbohydrates, resins, saponins, sterols and tannins were present in varied compositions in the aqueous extract and ethanolic extract of the L. inermis leaves and seeds ([19], [11] and [20]).

TLC profiling of Nigerian and Egyptian henna extracts gives an impressive result that shows 9 different bands of chemical compound $\mathrm{s}$, with $\mathrm{Rf}$ value of between a minimum of 0.20 to a maximum of 0.86 . The eluted compounds showed different colorations such as yellow corresponding with flavonoid behavior, orange corresponding to alkaloid, green corresponding to chlorophyll and purple corresponding to anthocyanin etc. The retention factors ( $\mathrm{Rf}$ ) for each band was recorded and presented in Table (2), graphical representation of the $\mathrm{Rf}$ values versus peaks is presented in fig. (1) and TLC chromatogram is presented in Figure (2). The Rf of the compounds detected between the Nigerian and Egyptian henna were found to be significantly similar. Priyanka et al., (2013) [15] reported that different Rf values of the compound in TLC plate reflect an idea about the polarity and solubility of chemical compound in the sample. However, in Sudan, Musa and Gasmelseed (2012) [21] identified Lawsone as an amorphous material appeared as an orange spot in the silica gel TLC $(\mathrm{Rf}=0.82)$ in visible light.

Table 2. Rf values of the chemical components in the Nigerian and Egyptian henna leaves extract

\begin{tabular}{ccc}
\hline $\begin{array}{c}\text { Peak } \\
\text { No. }\end{array}$ & Nigerian & Rf values \\
\hline 1 & 0.22 & Egyptian \\
2 & 0.33 & 0.20 \\
3 & 0.39 & 0.31 \\
4 & 0.47 & 0.38 \\
5 & 0.61 & 0.44 \\
6 & 0.69 & 0.61 \\
7 & 0.75 & 0.66 \\
8 & 0.78 & 0.72 \\
9 & 0.83 & 0.77 \\
\hline
\end{tabular}

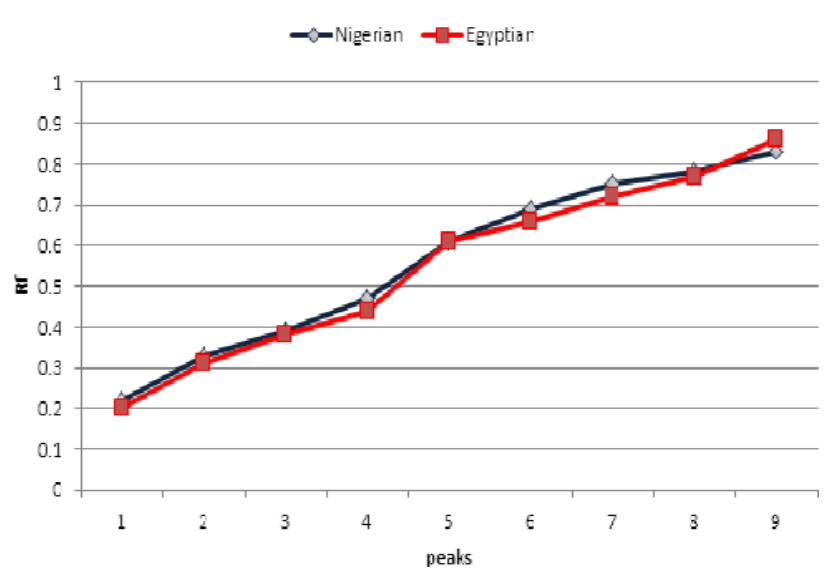

Fig 1. Graphical representation of the Rf vs. peak values of the chemical components in Nigerian and Egyptian henna n-hexane extract

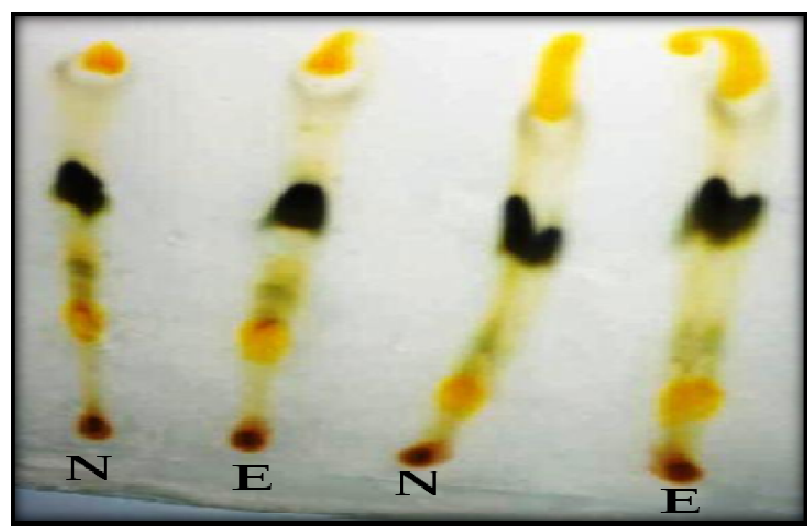

Fig 2. Thin layer chromatography (TLC) chromatogram showing the chemicals present in Nigerian and Egyptian henna leaves extract

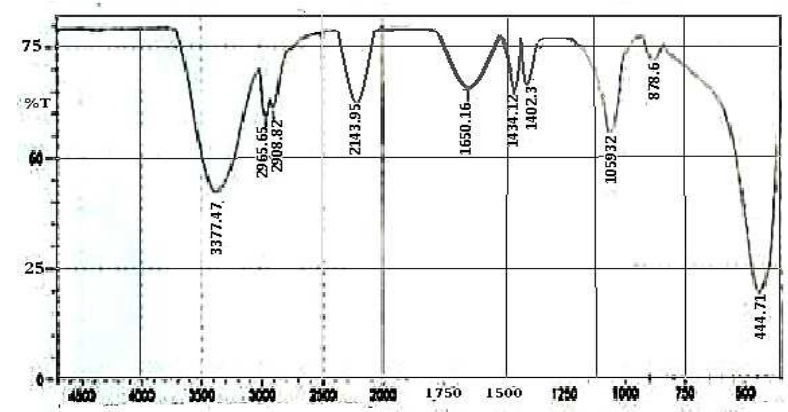

Fig 3. FTIR Spectrum of n-hexane extract of Nigerian L. inermis

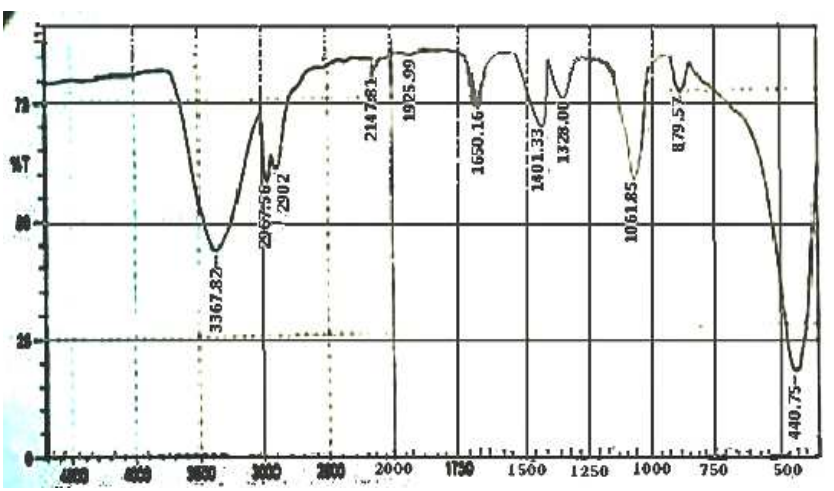

Fig 4. FTIR Spectrum of n-hexane extract of Egyptian L. inermis

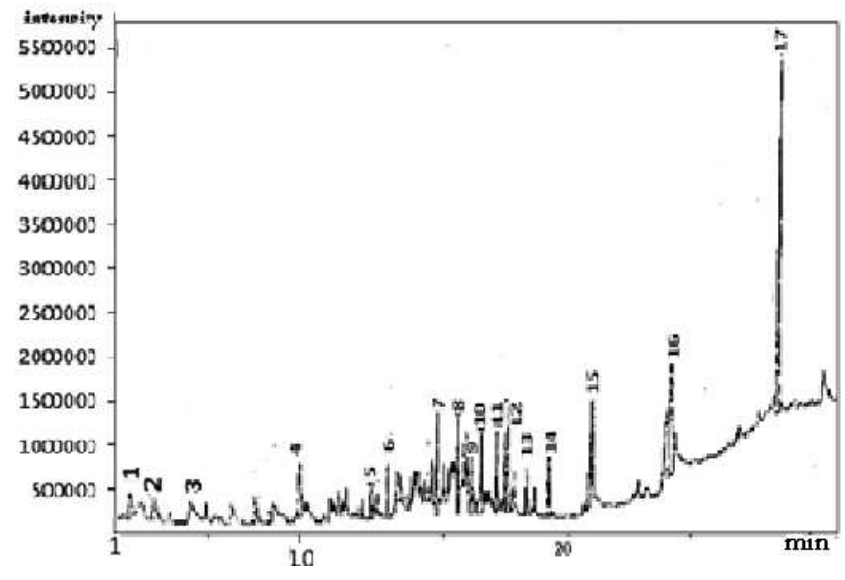

Fig 5. GCMS chromatogram of Nigerian henna leaves n-hexane extract 


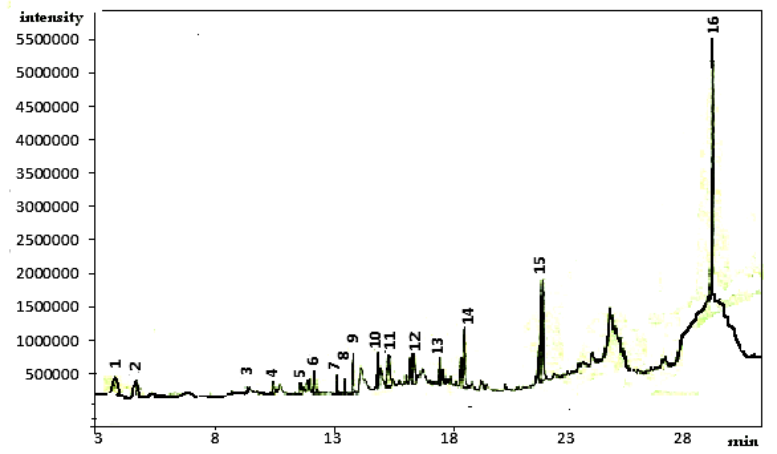

Fig 6. GCMS chromatogram of Egyptian henna leaves n-hexane extract

The FTIR peak values and functional groups were presented in Table (3), where the FTIR spectrum profile was illustrated. The FTIR spectrum in figure (3) and (4) confirmed the presence of 8 functional groups (aryl disulfides, aromatic ring, alkyl substituted ether, alcohols, alkane, quinone, and thiocyanate). Functional groups (alkanes, alkenes, ketones, esters, lactones, aromatics, symmetric nitro compounds, asymmetric nitro compounds, ethers, chalcones and aurones) were found in L. inermis leaves extract by Manikanta et al., (2013) [20]. Functional group $\mathrm{OH}$ was found to be present uniformly in all the samples. As $\mathrm{OH}$ group has got the ability of forming hydrogen bonding capacity, presence of $\mathrm{OH}$ group probably indicates the higher potential of hexane extract of henna towards inhibitory activity against microorganisms. Such a higher antimicrobial activity of the extract of many plants leaves have been already demonstrated [22]. However, functional group aryl disulfide has been confirmed to mitigate sulfur deposition in sour gas well [23]. Furthermore, the primary use of aromatic compounds, quinones, and alcohol as an anti-microbial agent has been observed in in vitro and in vivo studies ([24] and [25]).

Table 3. Fourier transforms infrared spectroscopy (FT-IR) Peak Values and Functional groups of Nigerian and Egyptian Lawsonia inermis Leaves extract

\begin{tabular}{cclcclc}
\hline No. & Peak values & $\begin{array}{c}\text { Nigerian henna } \\
\text { Functional group }\end{array}$ & Corr.area & Peak values & $\begin{array}{c}\text { Egyptian henna } \\
\text { Functional group }\end{array}$ & Corr.area \\
\hline 1 & 441.71 & Aryl disulfides & 0.138 & 440.75 & Aryl disulfides & 0.072 \\
2 & 878.8 & Aromatic ring & 1.315 & 579.57 & Aliphatic iodo & 1.975 \\
3 & 1059.60 & Alkyl substituted ether & 12.606 & 1061.85 & Alkyl substituted ether & 11.491 \\
4 & 1402.30 & Alcohol & 0.041 & 1328.03 & & 0.111 \\
5 & 1434.12 & Alkane & 0.013 & 1401.33 & Alcohol & 0.283 \\
6 & 1650.16 & Quinone & 0.001 & 1650.16 & Quinone & 3.996 \\
7 & 2143.96 & Thiocyanate & 0.589 & 1925.99 & Aromatic ring & 0.008 \\
8 & 2906.82 & unknown & 5.211 & 2147.81 & Thiocyanate & 0.280 \\
9 & 2965.65 & Alkane & 2.15 & $2902 . .00$ & Alkane & 4.855 \\
10 & 3377.47 & Alcohol & 85.966 & 2967.58 & Alkane & 3.143 \\
11 & 0.00 & unknown & 0.00 & 3367.82 & Alcohol & 66.772 \\
\hline
\end{tabular}

Table 4. Chemical components \% identified in Nigerian and Egyptian henna using $G C / M S$

\begin{tabular}{|c|c|c|c|}
\hline No. & Name of compound & N. & E. \\
\hline 1 & dl-Glyceraldehyde & 4.83 & 4.14 \\
\hline 2 & 2-Propanone, 1, 3-dihydroxy & 3.43 & 3.04 \\
\hline 3 & $\begin{array}{l}\text { 4H-Pyran-4-one, } 2,3 \text {-dihydro-3, } 5 \text { - } \\
\text { dihydroxy-6-methyl- }\end{array}$ & - & 1.97 \\
\hline 4 & Glycerane & 1.92 & - \\
\hline 5 & Coumarane & 2.90 & 6.89 \\
\hline 6 & 1, 2-Benzenedicarboxilic acid & 2.18 & - \\
\hline 7 & 1, 3-Indandione & 4.16 & - \\
\hline 8 & Benzomide & 2.09 & - \\
\hline 9 & Alpha-Guai & - & 2.30 \\
\hline 10 & Tetradecane & 1.25 & - \\
\hline 11 & 2-Acetyl Benzoic acid & 4.29 & 2.72 \\
\hline 12 & 3-Methyl-5-propyl & 3.87 & - \\
\hline 13 & Benzene dicarboxilicaciddiethyl ester & 7.04 & - \\
\hline 14 & $\begin{array}{l}\text { 2-(2-Isopropenylcyclopentylmethoxy) } \\
\text { tetrahydropyran }\end{array}$ & - & 5.18 \\
\hline 15 & Alpha-D-Glucopyranoside, metyl, alpha-D- & 7.75 & - \\
\hline 16 & Benzene, (1-methyldecyl) & - & 5.47 \\
\hline 17 & Benzene(1-propylnonyl) & - & 3.82 \\
\hline 18 & Benzene, (1-ethyldodecyl) & - & 7.67 \\
\hline 19 & Octanal, 2-(phenylmethylene) & 3.03 & - \\
\hline 20 & Benzene, (1-methyllundecyl) & - & 4.47 \\
\hline 21 & 1, 4-Naphtoquinone, 3-hydroxy & 9.87 & 7.40 \\
\hline 22 & Benzene, (1-ethyldecyl) & - & 2.94 \\
\hline 23 & 1, 4-Naphtoquinone, 2-amino & 19.35 & 4.64 \\
\hline 24 & Hexanoic acid & - & 8.57 \\
\hline 25 & $9,12,15$-Octadecatnen-1-ol & - & 11.69 \\
\hline 26 & Di-n-octyl phthalate & 22.03 & 17.09 \\
\hline
\end{tabular}

Interpretation on mass spectrum GC-MS was conducted using the database of National Institute Standard and Technology (NIST) having more than 62,000 patterns. The spectrum of the unknown component was compared with the spectrum of the known components stored in the NIST library. The name, molecular weight and structure of the components of the test materials were ascertained. Sixteen and seventeen compounds were identified in Nigerian and Egyptian Lawsonia inermis, respectively by GC-MS analysis. The active principles and their concentrations (\%) are presented in Table (4 and 5).

Table (5) displayed the percentage compositions of chemical compounds found common in both Nigerian and Egyptian henna samples. Lawsone (2-hydroxy 1, 2naphtoquinone) as the major chemical component of henna is one out of 7 common chemical compounds identified in both Nigerian and Egyptian henna. In Bulgaria, Reneta (2010) [26] reported that natural henna is known to contain lawsone, which is responsible for coloring orange-red. Area percentage of lawsone and peak height is higher in Nigerian sample (Table 4, 5 and 6) and (Fig. 4 and 5). In the comparative study of Lawsone contents in henna crops in spring and winter, between rain-fed and irrigated conditions at University of Rajasthan, Jaipur, India by Upadhyay et al., (2010) [27], it is clear that the rain-fed 
condition induce more of Lawsone content than the irrigatedcrop. However, the variation in the percentages of Lawsone between Nigerian and Egyptian samples 9. 87\% and $7.40 \%$ respectively was as a result of the first is rain fed while the second is irrigated, it can therefore, be concluded that Nigerian henna is better than Egyptian sample based on the lawsone content. Other common chemicals identified between Nigerian and Egyptian henna were; dl-Glyceraldehyde, 2-Propanone, 1, 3-dihydroxy, Coumarane, 2-Acetyl Benzoic acid, 1, 4-Naphtoquinone, 3hydroxy, 1, 4-Naphtoquinone, 2-amino. However in another research in India, Hema et al., (2010) [9] identified six compounds in henna, and the prevailing compounds were Alpha-D-Glucopyranoside, methyl (51.73\%) and 1, 4-Naphthalenedione, 2-hydroxy- (19. 19\%). In addition to their findings in this research Di-n-octyl phthalate was found to be the most prevailing compound in both Nigerian and Egyptian samples $22.03 \%$ and $17.09 \%$ respectively. In all the compounds that are common between the samples, percentage was higher in Nigerian sample except for coumaran which was vice versa (6. 89\% in Egyptian and 2. $9 \%$ in Nigerian samples). Naphthoquinones are products of bacterial and fungal as well as high-plants secondary metabolism; Juglone, lawsone, and plumbagin are the most widespread compounds. They have significant antibacterial, antifungal, antiviral, insecticidal, anti-inflammatory, and antipyretic properties [25].

Table 5. Comparative percentages of the common compounds between Nigerian and Egyptian henna

\begin{tabular}{llll}
\hline \multirow{2}{*}{ No. } & Compound & \multicolumn{2}{c}{$\%$} \\
\hline 1 & dl-Glyceraldehyde & 4.83 & 4.14 \\
2 & 2-Propanone, 1, 3-dihydroxy & 3.43 & 3.04 \\
3 & Coumarane & 2.90 & 6.89 \\
4 & 2-Acetyl Benzoic acid & 4.29 & 2.72 \\
5 & 1, 4-Naphtoquinone, 3-hydroxy & 9.87 & 7.40 \\
6 & 1, 4-Naphtoquinone, 2-amino & 19.35 & 4.64 \\
7 & Di-n-octyl phthalate & 22.03 & 17.09 \\
\hline
\end{tabular}

Table (6) shows 10 chemical compounds that are unique to each Egyptian and Nigerian samples. Their presence and absence in one another is base on their geographical location and the time at which they where harvested. The comparative study by Ashokkumar and Ramaswamy (2013) [22] confirms that phytochemicals present in Cuscuta reflexa parasite depends on nature of host as their source of nutriens. Therefore, base on this result, the variations in chemical compounds present in Nigerian and Egyptian henna depend on the climatic conditions of the cultivation area and season at which the samples were collected. Different compounds are present in L. inermis in two different countries thus it is concluded that variation in phytochemicals in $L$. inermis is cultivation area dependent. Further study need to be undertaken to investigate the biological activity and other phytochemicals present in $L$. inermis grown in other countries.
Table 6. Chemical compounds identified as unique to Nigerian or Egyptian Lawsonia inermis (henna)

\begin{tabular}{|c|c|c|c|c|}
\hline No. & $\begin{array}{l}\text { Nigerian } \\
\text { Compound }\end{array}$ & $\%$ & $\begin{array}{l}\text { Egyptian } \\
\text { Compound }\end{array}$ & $\%$ \\
\hline 1 & Glycerane & 3.43 & $\begin{array}{l}\text { 4H-Pyran-4-one, 2, 3-dihydro- } \\
\text { 3, 5-dihydroxy-6-methyl- }\end{array}$ & 1.75 \\
\hline 2 & $\begin{array}{l}1,3- \\
\text { Indandione }\end{array}$ & 1.92 & Alpha-Guai & 2.29 \\
\hline 3 & $\begin{array}{l}1,2- \\
\text { Benzenedicar } \\
\text { boxilic acid }\end{array}$ & 2.00 & $\begin{array}{l}\text { 2-(2- } \\
\text { Isopropenylcyclopentylmethox } \\
\text { y)tetrahydropyran }\end{array}$ & 7.16 \\
\hline 4 & Benzomide & 3.15 & Dodecane 2-phenyl & 6.74 \\
\hline 5 & Tetradecane & 2.72 & Benzene(1-propylnonyl) & 4.07 \\
\hline 6 & $\begin{array}{l}\text { 3-Methyl-5- } \\
\text { propyl }\end{array}$ & 2.50 & Benzene, (1-ethyldodecyl) & 5.52 \\
\hline 7 & Benzomide & 5.14 & Benzene, (1-methyllundecyl) & 5.73 \\
\hline 8 & $\begin{array}{l}\text { Benzenedicar } \\
\text { boxilicaciddie } \\
\text { thyl ester }\end{array}$ & 4.50 & Benzene, (1-ethyldecyl) & 3.43 \\
\hline 9 & $\begin{array}{l}\text { Alpha-D- } \\
\text { Glucopyranos } \\
\text { ide, metyl, } \\
\text { alpha-D- }\end{array}$ & 4.52 & Hexanoic acid & 7.49 \\
\hline 10 & $\begin{array}{l}\text { Octanal, 2- } \\
\text { (phenylmethyl } \\
\text { en }\end{array}$ & 4.03 & $9,12,15$-Octadecatnen-1-ol & 7.95 \\
\hline
\end{tabular}

\section{Conclusion}

The result of the present study supports the traditional usage of the studied L. inermis and suggests that the plant extracts possess compounds used in traditional medicine. Therefore, results of the present study comprised rational evidence, scientific justification and support to the equality of the use of L. inermis in both countries in cosmetics, pharmacy and traditional medicine. Wherein a detailed research work of characterization and standardization is required for this potential plant in developing various formulations from its extract, which can ultimately be beneficial for human being as well as animals.

\section{References}

[1] Abdelraouf, A. Amany and A. Nedaa, "Antibacterial, Antifungal and Synergistic Effect of Lawsonia inermis, Punicagranatum and Hibiscus sabdariffa g" Annals of Alquds Medicine. 2011 (7): 33-41.

[2] Z . Emin, and O. Mehmet, "A Miracle Plant for the Herbal Pharmacy; Henna (Lawsonia inermis)", International Journal of Pharmacology", 2012. 8: 483-489.

[3] G. Awek, and S. TapapulLekoyiet, "Lawsonia inermis L". National Museums of Kenya, Nairobi, Kenya, 2005 Pp 722.

[4] M. A. Ayatollahi, H. Abdolahi, and N. Kazemii, "Investigation of antifungal activity of 10 methanol extracts of medicinal herbs." Journal of Kerman University Medical Sciences, 1996, 3(3): 115-22.

[5] L. G. Gibbons, N. G. Gopalla, R. H., Hunter, A . K., Kerr, and P. M. Mulrey, "Plants encyclopedia". First American Edition, US. 2004, Pp232. 
[6] J. E. Simon, A. F. Chadwick, and L. E. Craker, "The scientific Literature on selected herbs," Aromatic and Medicinal plants of the Temperate Zone. Archon Books, Hamden city herbs: An indexed bibliography, 1984, Pp770.

[7] M. E. Tattoo, "Analysis of the henna plant," Journal of Horticultural Science and Biotechnology, 2006, 77(1): 67-72.

[8] M. R. Iyer, S. C. Pal, V. S. Kasture and S. B. Kasture, "Effect of Lawsonia inermis on memory and behaviour mediated via Monoamine neurotransmitters," Indian Journal of Pharmacology, 1998, 30(3):181-185.

[9] R. Hema, S. Kumaravel and N. Gomathi, "Gas Chromatography Mass Spectroscopic analysis of Lawsonia inermis Leaves," New York Science Journal, 2010. 3(12): 99-101.

[10] M. Ibrahim, A. J. Hameed, and A. Jalbout, "Molecular Spectroscopic Study of River Nile Sediment in the Greater Cairo Region,” Applied Spectroscop, 2008, 62(3): 306-311.

[11] P. Arun, K. G. Purushotham, J. Jayarani and V. Kumari, "In vitro Antibacterial activity and Flavonoid contents of Lawsonia inermis (Henna)," International Journal of Pharmaceutica Technology Research, 2010. 2(2):1178-1181.

[12] Fariba B., R. Hassan and E. Homeyra, "In vitro study of the effects of henna extracts (Lawsonia inermis) on Malassezia species," Jundishapur Journal of Microbiology, 2010, 3(3): 125-128.

[13] H. Kawo and A. M. Kwa, "Phytochemical screening and antibacterial activity of the aqueous extracts and fractions of ethanolic extracts of Lawsonia inermis Leaf," International Research Journal of Microbiology, 2011, 2(12): 510-516.

[14] Evans W. C. and Trease (1999). "Pharmacognosy," 14th Edition, Bailiere Tindal W. B. Sauders company ltd; London, Pp. 224-275.

[15] Priyanka P. and I. Rakesh, andR. Upadhyay "Physicochemical and preliminary phytochemical screening of Psoralea corylifolia," Arch. Appl. Sci. Res, 2013, 5 (2):261265.

[16] O. Aiyelaagbe and P. M. Osamudiamen, "Phytochemical Screening for Active Compounds in Mangifera indica Leaves from Ibadan, Oyo State," Plant Sciences Research, 2009, 1(2): 11-13.

[17] P. M. Denwick, "Natural Products" A Biosynthetic
Approach. 2nd Edn., John Wiley and Sons, Ltd., England, 2002, Pp: 241-243.

[18] E. Heslem, "Plant Polyphenol: Vegetal Tannin TelistedChemistry and Pharmacology of Natural Products," 1st Edn., Cambridge University Press, Cambridge, Massachusetts, 1989, pp: 169.

[19] Y. V., Singh, S., Kumar and M. Singh, "Agro History, Uses, Ecology and Distribution of Henna (Lawsonia inermis)," Jodpur, India. Central and Arid-zone Research Institute, 2005, Pp 11-12.

[20] Manikanta, K. Akshata, K. Rohini, K. Azeemuddin and N. Manjunath, "Analytical Estimation of Secondary Metabolites In Lawsonia inermis Leaves," American Journal of Pharmtech Research, 2013, 3(5): 2249-3387.

[21] E. Musa, and G. A. Gasmelseed, "Characterization of Lawsonia inermis (Henna) as Vegetable Tanning," Journal of Forest Products \& Industries, 2012, 1(2): 35-40.

[22] R. Ashokkumar, and M. Ramaswamy, "Comparative study on the antimicrobial activity of leaf extracts of four selected Indian medicinal plants against Pseudomonas aeruginosa, Pseudomonas fluorescens, Penicillium chrysogenum and Penicillium restrictum," Journal of Chemical, Biological and Physical Sciences, 2013, 3(2): 1376-1381.

[23] D. C. Peter, K. L. Lesage and P. Sarkar, "Application of aryl disulfides for the mitigation of sulfur deposition in sour gas wells," Journal of Energy Fuels, 1989, 3 (3): 315-320.

[24] S. Collins, S. C. Sumner, S. J. Borghoff and M. A. Medinsky, "A physiological model for tert-amyl methyl ether and tertamyl alcohol Hypothesis testing of model structures". Toxicological sciences. Journal of the Society of Toxicology, 1999, 49 (1): 15-28.

[25] Abulyazid, M. E. Elsayed Mahdy and A. M. Ragaa, "Biochemical study for the effect of henna (Lawsonia inermis) on Escherichia coli Arabian Journal of Chemistry, 2013, 3 (6): 265-273.

[26] G. Reneta, "Determination of natural colorants in plant extracts by high-performance liquid chromatography J. Serb. Chem. Soc., 2010, 75 (7) 903-915.

[27] Upadhyay, A. K., Dhaker, K. P. Singhand A. Kumar, "Phytochemical analysis and influence of edaphic factors on lawsone content of Lawsonia inermis," Journal of Phytology, 2010, 2(6): 47-54. 